\title{
A Rare Case of Delayed Onset Tunneling Disc Herniation in the Lumbar Spine
}

\author{
Toru Maeda ${ }^{12)}$, Kosaku Higashino ${ }^{3)}$, Satoshi Hattori ${ }^{1)}$ and Koichi Sairyo ${ }^{2)}$ \\ 1) Orthopedic Surgery, Nagoya Tokushukai General Hospital, Aichi, Japan \\ 2) Department of Orthopedics, Institute of Biomedical Sciences, Tokushima University Graduate School, Tokushima, Japan \\ 3) Department of Orthopedics and Rehabilitation, Shikoku Medical Center for Children and Adults, Kagawa, Japan
}

\author{
Keywords: \\ tunneling lumbar disc herniation, low back pain, lumbar spine
}

\section{Medical history}

A 66-year-old man visited our hospital because of recurring low back pain. On his first visit to our hospital at the age of 63 years, he complained of only low back pain and had no other symptoms such as leg pain, numbness, or weakness of the lower extremities. The pain was mild, and the visual analog scale (VAS) score for pain was around 2-3 out of 10 . He is real estate agent. He did not have any medical history and played golf occasionally. However, 3 years after the first treatment, he experienced severe low back pain and had difficulty in walking. The pain was incapacitating, reaching 8-10 on the VAS.

\section{Physical and neurological examinations}

Lumbar range of motion was restricted due to pain, and changes in body posture exacerbated the pain. In particular, he complained of strong pain during flexion. A neurological deficit was present as shown by progressive muscle weakness. Hypoesthesia with numbness was present in the left lateral lower leg. The manual muscle test result was grade 4 for the left extensor and left flexor hallucis longus muscles. There was hypoesthesia over the left L5 lesion, and the left deep Achilles tendon reflex was diminished. The straight leg raise test to $30^{\circ}$ was positive on the left side.

\section{Radiological findings}

During the first examination 3 years earlier, T1- and T2weighted magnetic resonance imaging (MRI) showed no Schmorl's nodes or Modic changes in the lumbar interverte- bral disc and endplates at the L4/5 level (Fig. 1).

Three years later, follow-up X-ray, computed tomography (CT), and MRI indicated tunneling lumbar disc herniation via the middle upper endplate at L5 through the posterior wall at L5. A herniated mass compressed the left L5 and S1 nerve root in the spinal canal (Fig. 2A, 2B, 2C).

\section{Diagnosis and treatment}

We performed decompression and removal of the herniated mass at the L4/5 level. Operative findings showed that there were masses of different sizes in the range of $13 \mathrm{~cm}$ in length (Fig. 3). The posterior wall of the left vertebra at L5 had a single hole.

Histological examination of the surgical specimen showed nucleus tissue with degeneration and some chondrocytes without inflammatory cells.

\section{Postoperative course}

One year after surgery, follow-up MRI showed degenerative change of the lumbar disc at L4/5. In the 1 year following the second episode, he has remained pain free. X-ray, $\mathrm{CT}$, and T2-weighted MRI at the final follow-up showed degenerative tissue of the tunneled lesion at the L5 vertebra (Fig. 4A, 4B, 4C).

\section{Discussion}

Our rare case highlights that the lumbar disc may cause tunneling herniation without typical Schmorl's nodes. Coulier et al. reported a tunneling transvertebral Schmorl's node of the superior endplate at the L3 vertebra ${ }^{1}$. 


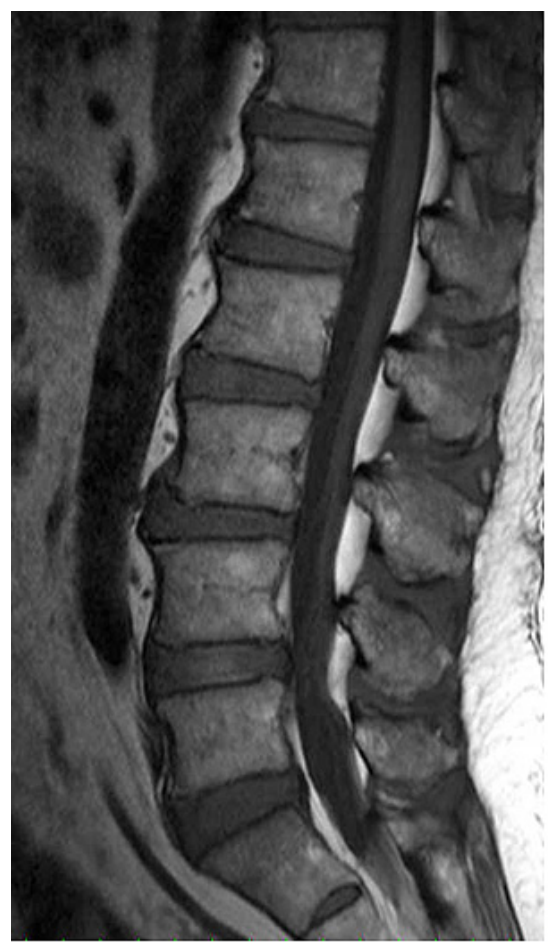

T1w sagittal

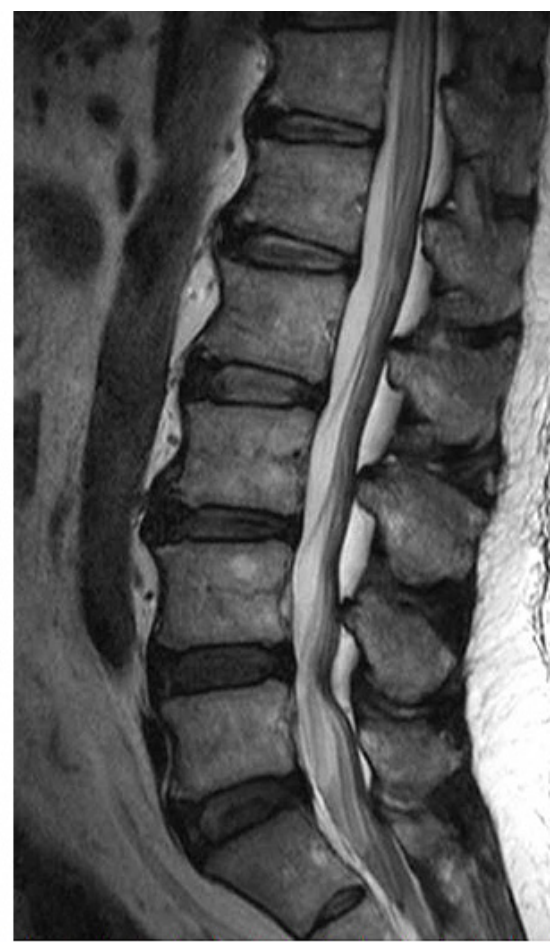

T2w sagittal

Figure 1. T1- and T2-weighted MRI show no Schmorl's nodes or Modic changes in the lumbar vertebral endplates at the L5 level.

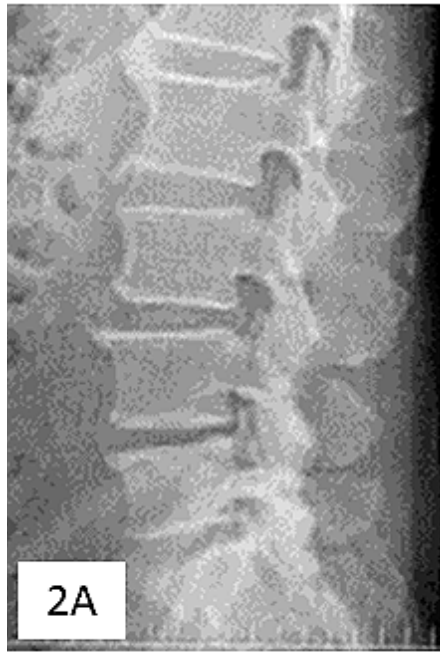

X-ray

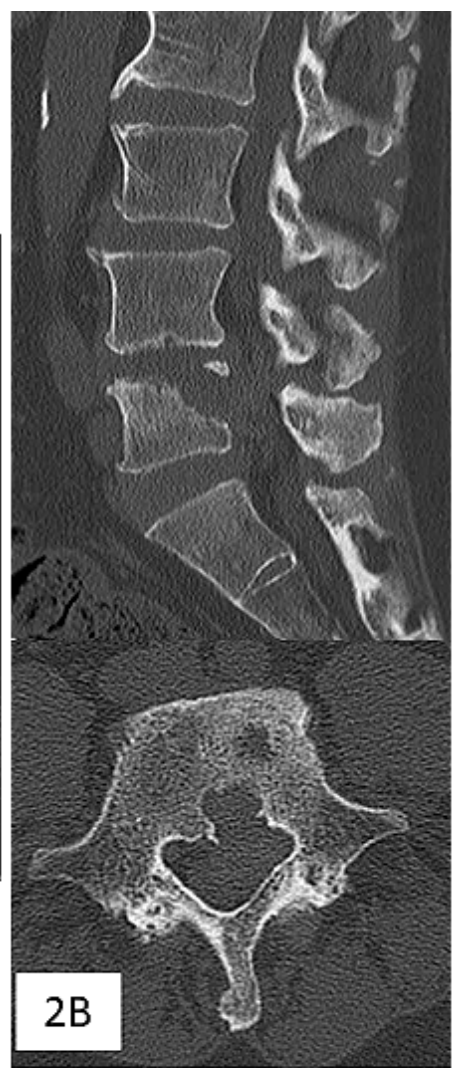

CT

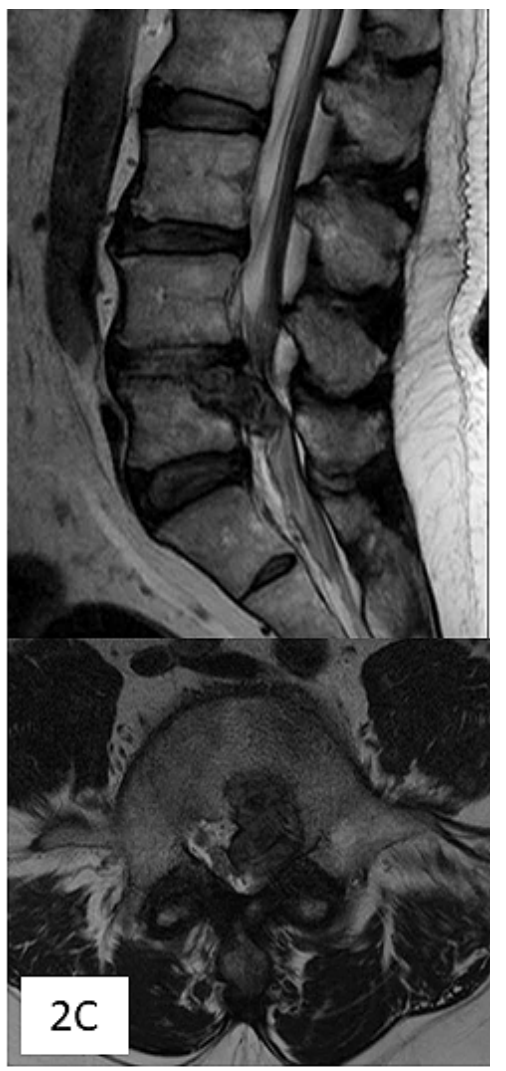

T2-weighted MRI

Figure 2. Follow-up X-ray, CT, and MRI show tunneling lumbar disc herniation via the middle upper endplate at L4 through the posterior wall at L5. 
In our previous study, we reported that lesions of the lumbar endplate are sometimes observed in the vertebrae of children and adolescents ${ }^{2,3}$. Excessive mechanical stress applied to the central area or the apophyseal ring of lumbar vertebrae may lead to an abnormal vertebral shape ${ }^{4,5}$. Our previous study showed that for the middle type, multiple lesions were seen, and lesions affecting the upper level vertebrae were more prevalent ${ }^{6}$.

Some studies have found that the prevalence of Schmorl's nodes was higher in the elderly population than in the

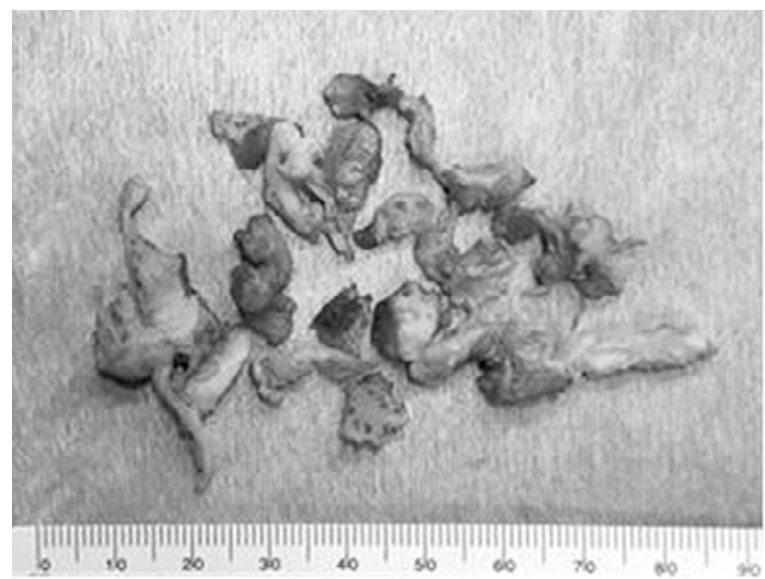

Figure 3. Excised specimens of lumbar disc herniation show masses of different sizes ranging $1-3 \mathrm{~cm}$ in length. younger population ${ }^{7.8}$. Although many studies have reported that Schmorl's nodes occur when the cartilaginous endplate of the vertebral body is disrupted, the peak onset of Schmorl's nodes is still unclear ${ }^{8,9}$. Our case differs from cases of Schmorl's nodes in children and adolescents. A biomechanical study reported that the strength of the central and posterior regions of the endplate was less than that of another position on the endplate ${ }^{10}$. The present case suggests that the protrusion of the nuclear material prolapsed into the vertebral body and through the posterior wall due to degenerative changes of the cartilaginous endplate.

Conflicts of Interest: The authors declare that there are no relevant conflicts of interest.

Author Contributions: Toru Maeda contributed to the conception and design of the work and drafted the manuscript. Kosaku Higashino reviewed and rewrote the manuscript. Satoshi Hattori is in agreement to be accountable for all aspects of the manuscript. Koichi Sairyo approved the final version of the manuscript.

Informed Consent: Informed consent was performed.

\section{References}

1. Coulier B, Ghosez JP. Lumbar radiculopathy caused by a tunneling transvertebral Schmorl's node. Skeletal Radiol. 2002;31(8):
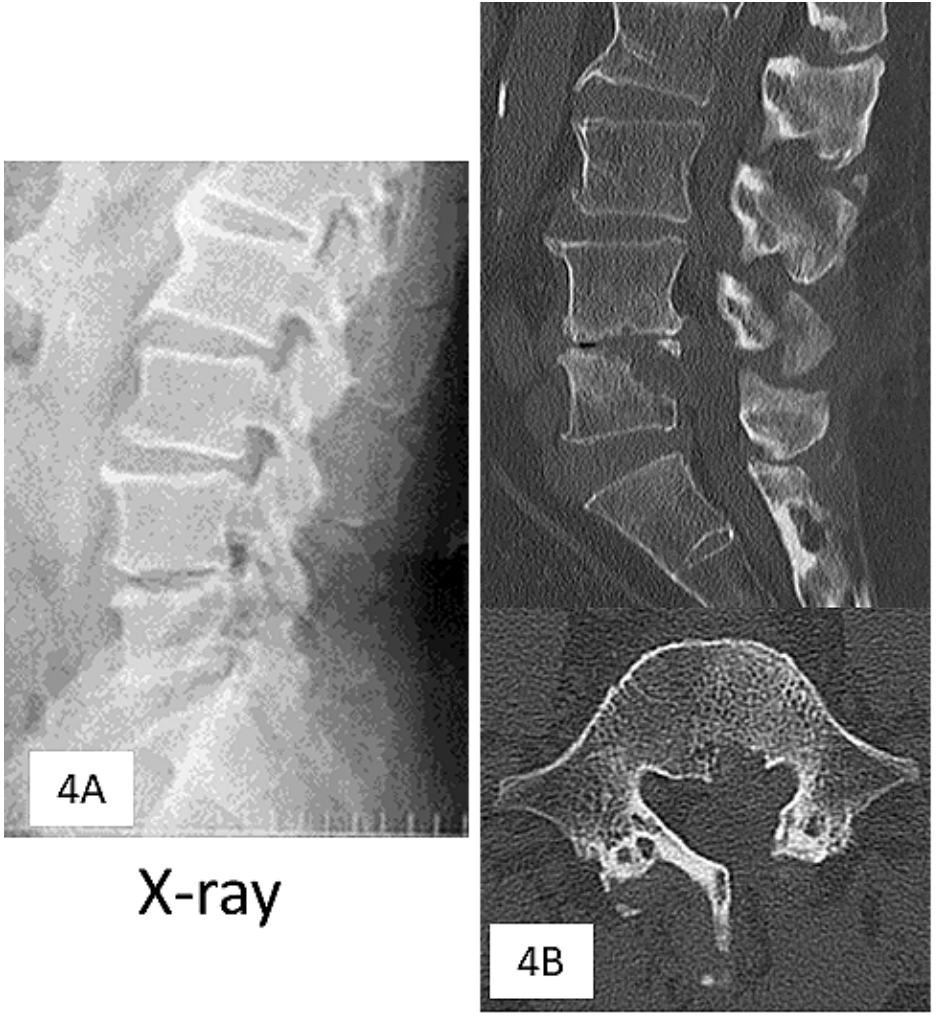

CT

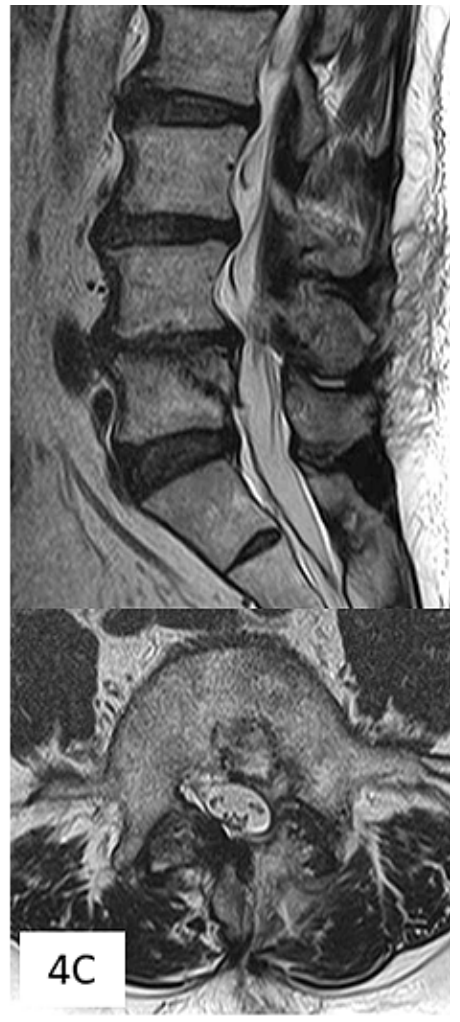

T2-weighted MRI

Figure 4. X-ray, CT, and MRI taken at the final follow-up show degenerative tissue of the tunneling lesion at the L5 vertebra. 
484-7. doi: 10.1007/s00256-002-0525-9. PubMed PMID: 12172599

2. Ikata T, Morita T, Katoh S, et al. Lesions of the lumbar posterior end plate in children and adolescents. An MRI study. J Bone Joint Surg Br. 1995;77(6):951-5. Epub 1995/11/01. PubMed PMID: 7593113.

3. Higashino K, Sairyo K, Katoh S, et al. Long-term outcomes of lumbar posterior apophyseal end-plate lesions in children and adolescents. J Bone Joint Surg Am. 2012;94(11):e74. Epub 2012/05/ 29. doi: 1169821 [pii] 10.2106/JBJS.K.00343. PubMed PMID: 22637214.

4. Siffert RS. Classification of the osteochondroses. Clin Orthop Relat Res. 1981(158):10-8. PubMed PMID: 7273506.

5. Sairyo K, Katoh S, Ikata T, et al. Development of spondylolytic olisthesis in adolescents. Spine J. 2001;1(3):171-5. Epub 2003/11/ 01. doi: S1529-9430(01)00018-3 [pii]. PubMed PMID: 14588344.

6. Uraoka H, Higashino K, Morimoto M, et al. Study of lesions of the lumbar endplate based on the stage of maturation of the lumbar vertebral body: the relationship between skeletal maturity and chronological age. Eur J Orthop Surg Traumatol. 2018;28(2):1837. doi: 10.1007/s00590-017-2032-7. PubMed PMID: 28918493.
7. Pfirrmann CW, Resnick D. Schmorl nodes of the thoracic and lumbar spine: radiographic-pathologic study of prevalence, characterization, and correlation with degenerative changes of 1,650 spinal levels in 100 cadavers. Radiology. 2001;219(2):368-74. doi: 10.1148/radiology.219.2.r01ma21368. PubMed PMID: 11323459.

8. Hamanishi C, Kawabata T, Yosii T, et al. Schmorl's nodes on magnetic resonance imaging. Their incidence and clinical relevance. Spine (Phila Pa 1976). 1994;19(4):450-3. PubMed PMID: 8178234.

9. Wagner AL, Murtagh FR, Arrington JA, et al. Relationship of Schmorl's nodes to vertebral body endplate fractures and acute endplate disk extrusions. AJNR Am J Neuroradiol. 2000;21(2): 276-81. PubMed PMID: 10696008.

10. Lowe TG, Hashim S, Wilson LA, et al. A biomechanical study of regional endplate strength and cage morphology as it relates to structural interbody support. Spine (Phila Pa 1976). 2004;29(21): 2389-94. PubMed PMID: 15507800.

Spine Surgery and Related Research is an Open Access journal distributed under the Creative Commons Attribution-NonCommercial-NoDerivatives 4.0 International License. To view the details of this license, please visit (https://creativeco mmons.org/licenses/by-nc-nd/4.0/). 